\title{
Grafos, algoritmos e métricas. Como seguir rastros nas mídias sociais?
}

\author{
Romulo Fernando Lemos Gomes' \\ I - PUC/SP \\ São Paulo (SP), Brasil \\ RECUERO, R.; BASTOS, M.; ZAGO, G. \\ Análise de redes sociais \\ para a mídia social. \\ Porto Alegre: Sulina, 2015, 182 p.
}

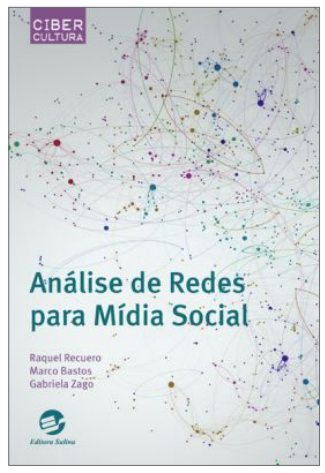

Resumo: Em Análise de Redes para Mídia Social, os pesquisadores Raquel Recuero, Marco Bastos e Gabriela Zago, do grupo de pesquisa Mídia, Discurso e Análise de Redes Sociais (MIDIARS), da Universidade Católica de Pelotas (UCPel), apresentam possíveis caminhos teóricos e epistemológicos para a compreensão do social forjado no digital. A resposta central dos autores aponta para a aplicação da Análise de Redes Sociais (ARS), associada a elementos da teoria dos grafos e da sociometria, aos estudos de redes sociais na internet.

Palavras-chave: redes sociais; mídia social; comunicação digital.

Abstract: Graphs, algorithms and metrics. How to follow traces in social media? In Análise de Redes para Mídia Social, researchers Raquel Recuero, Marco Bastos and Gabriela Zago, from MIDIARS (Media, Discourse and Social Network Analysis Research Group), of UCPel (Catholic University of Pelotas), present theoretical and epistemological paths for an understanding of the social constitution in digital space. The central response of the authors points to the application of ARS (Analysis of Social Media), associated with elements of graph theory and sociometry, to the studies of social networks on the Internet.

Keywords: social networks; social media; digital communication. 
Somente no Brasil, 117 milhões de usuários estão conectados pela mídia social Facebook (COSSETTI, 2018); outros 50 milhões têm contas no Instagram (FOLHA DE S.PAULO, 2018) e 82 milhões formam a base de usuários do YouTube (BRASIL ECONÔMICO, 2018). Curtidas, comentários, compartilhamentos, visualizações de vídeos, agendamento dos eventos mais próximos, mobilização política. A cada movimento desses usuários, rastros digitais são deixados no ciberespaço, gerando dados numa quantidade sem precedentes. O digital impactou na construção da vida social, com efeitos nos campos científicos interessados em seguir esses rastros e desvelar padrões sociais neles manifestos. Mas, as mudanças acentuadas de cunho tecnoculturais também têm exigido soluções teórico-metodológicas renovadas. Está posto, desse modo, um dos maiores desafios, atualmente, à área da Comunicação, assim como às demais Ciências Sociais.

Os pesquisadores Raquel Recuero, Marco Bastos e Gabriela Zago, do grupo de pesquisa Mídia, Discurso e Análise de Redes Sociais (MIDIARS), da Universidade Católica de Pelotas (UCPel), debruçaram-se sobre essa questão e apresentaram, no livro Análise de Redes para Mídia Social, possíveis caminhos teóricos e epistemológicos a serem trilhados para a compreensão do social forjado no digital. A resposta central dos autores aponta para a aplicação da Análise de Redes Sociais (ARS), associada a elementos da teoria dos grafos e da sociometria, aos estudos de redes sociais na internet. Essa abordagem possui viés estruturalista e propõe-se a abranger investigações sobre os agrupamentos sociais, com especial atenção às relações entre os indivíduos.

Para a ARS são as conexões envolvendo os diversos atores que constituem a estrutura do tecido social. Por isso, o interesse dessa abordagem direciona-se às redes formadas pelos indivíduos e suas relações. Esse tipo de estudo é realizado há mais de um século, com autores contrários ao cartesianismo. Sua gênese remonta aos escritos do antropólogo RadcliffeBrown, que elaborou o conceito de "estrutura social". Ao ser transposta para a análise das interações na internet, portanto, o foco da ARS não pode ser direcionado propriamente aos sites de redes sociais, cujo papel é de suporte, de plataforma de comunicação. O pesquisador que se servir dessa abordagem deve voltar-se ao "complexo universo de negociação de normas e formas de interação" (RECUERO; BASTOS; ZAGO, 2015, p. 24).

Ao trazer esse fenômeno à baila, Recuero, Bastos e Zago (2015) preferem utilizar o termo mídia social, escapando, assim, de se referir somente à ferramenta, para expandir o conceito à apropriação das redes sociais na internet pelos usuários. Dessa forma, mídia social designa a complexidade das interações mediadas pelo digital, desde os filtros criados por robôs para que um conteúdo chegue ou não a determinado usuário, as conexões que possibilitam a circulação de informações e a chance de replicá-las para outras redes, a definição do que ganha mais relevância e, com isso, o alcance de mais usuários. Ou seja, a mídia social não diz respeito apenas ao suporte, mas à interação como um todo.

Os autores consideram as redes sociais na internet uma tradução das redes sociais off-line, mas com novos elementos e dinâmicas. Primeiro, porque ficam registros on-line 
das conversações e trocas sociais; e, segundo, porque a representação do grupo social no ciberespaço altera o grupo em si. Como exemplo, os autores citam o fato de os laços não serem desgastados por falta de contato cotidiano e presencial.

No livro, Recuero, Bastos e Zago (2015) discutem esses elementos conceituais básicos, abrindo caminho para a incorporação de terminologias e técnicas herdadas da teoria dos grafos. A análise de redes para mídia social, utilizando a base metodológica da ARS, pressupõe o uso de um conjunto de métricas e técnicas, que servem para descrever a relação elação entre nós (atores, vértices) e suas conexões (arestas). Essa abordagem é sempre sustentada em dados empíricos, representados em gráficos e imagens.

Um dos pontos mais importantes que precisa ser compreendido a respeito dos grafos é seu papel como representação. Como representação de um sistema complexo como uma sociedade, o grafo é, frequentemente, uma fotografia da estrutura em um dado momento e não uma fotografia. Assim, é preciso ter em mente que dificilmente uma representação estática dá conta da complexidade de um sistema social (Ibdem, p. 50).

Desde sua criação, os estudos de rede recorrem a modelos matemáticos. A novidade quando de sua incorporação nas pesquisas do ciberespaço foi a inclusão e total dependência do uso de modelos computacionais. Talvez nesse ponto resida a maior dificuldade para os oriundos do campo comunicacional, desfamiliarizados com a linguagem de programação de computadores. Na obra de Recuero, Bastos e Zago (2015) não existe pretensão de ensinar a programar, mas os autores fazem um inventário das principais ferramentas e algoritimos utilizados para a coleta e análise de dados em redes na internet, apontando vantagens e desvantagens de cada uma.

Para a coleta de dados no Twitter, por exemplo, está sendo usado o YourTwapperKeeper (yTK); o Labic é aplicado para Twitter e Facebook; e o Netvizz para Facebook. O yTK e o Netvizz geram dados, mas precisam do auxílio de outras ferramentas no momento da análise. Esse trabalho também pode ser feito por uma ferramenta open source, o Gephi, que toma como parâmetros as métricas de ARS. A relação de suportes se estende, inclusive com o alerta de que alguns requerem softwares e computador servidor de alto desempenho. Além dessas orientações sobre ferramentas, parte da obra é dedicada a orientar, metodologicamente, sobre a delimitação do tipo de dado e a forma de coletá-lo, que pode ser por uma rede egocentrada (quando determinado nó, chamado ego, estará mais ao centro do grafo); ou de acordo com o grau dos nós (indegree ou grau de entrada; outdegree ou o grau de saída; ou grau de intermediação, quando o nó é ponte entre vários grupos de nós), entre outras métricas.

O livro termina com exercícios práticos de análise de rede, tendo como recorte os debates eleitorais dos candidatos à Presidência do Brasil, em 2014. A proposta era mostrar, por meio dos grafos, como os candidatos repercutiram suas participações em 
debates transmitidos por emissoras de televisão. Essa é uma das espécies de pesquisas propícias para a abordagem ARS. Os autores reconhecem, entretanto, que essa metodologia tem como foco a estrutura dos fenômenos, o que pouco pode contribuir para pesquisas que objetivam analisar discursos nas redes sociais na internet, por exemplo. Admitindo essa limitação e tendo às mãos objetos adequados a essa metodologia, os caminhos propostos por Recuero, Bastos e Zago (2015) podem ser bem aproveitados por pesquisadores e profissionais que queiram seguir os rastros deixados pelos usuários das mídias sociais.

\author{
Romulo Fernando Lemos Gomes é doutorando no Programa \\ de Estudos Pós-Graduados em Comunicação e Semiótica, da \\ PUC/SP e jornalista do Instituto Federal de Educação, Ciência \\ e Tecnologia do Maranhão (IFMA) - Campus São Luís. \\ romulogomes83@gmail.com
}

\title{
Referências
}

BRASIL ECONÔMICO. Youtube chega a 82 milhões de usuários no Brasil. Disponível em: <http:// tecnologia.ig.com.br/2016-10-05/youtube-usuarios.html>. Acesso em: 21 fev. 2018.

COSSETTI, M. C. Facebook chega a 2 bilhões de usuários. Disponível em: <https://www.techtudo. com.br/noticias/2017/06/facebook-chega-a-2-bilhoes-de-usuarios.ghtml>. Acesso em: 21 fev. 2018.

FOLHA DE S.PAULO. Com 50 milhões de usuários, Brasil é segundo no ranking do Instagram. Disponível em: <http://www1.folha.uol.com.br/mercado/2017/10/1931057-com-50-milhoes-deusuarios-brasil-e-segundo-no-ranking-do-instagram.shtml>. Acesso em: 21 fev. 2018. 